\title{
Analysis of Taklinear Performance and Integer Linear Programming Models in Nurses Scheduling Problems
}

\author{
Junerdi Nababan \\ University Sumatera Utara \\ Medan, Indonesia \\ paynet.netpay@gmail.com
}

\author{
Tulus \\ University Sumatera Utara \\ Medan, Indonesia \\ tulus@usu.ac.id
}

\author{
Zakarias Situmorang \\ University Sumatera Utara \\ Medan, Indonesia \\ Zakarias65@yahoo.com
}

Submitted: Mar 13, 2020

Accepted: Mar 26, 2020

Published: Apr 6, 2020

\begin{abstract}
Almost all hospitals schedule nurses' work shifts manually, which is not effective, mistakes in scheduling nurses in hospitals can make them not work optimally so that they are prone to making mistakes and will endanger every patient in the hospital. In the research will be proposed integer linear programming model and branch and bound method, the purpose of this study is to develop an optimization model of nurse scheduling problems at the hospital. The optimization model will minimize the total deviation of nurses' working days from the standard workdays, the optimization model implemented in hospitals is processed using LINGO software.
\end{abstract}

Keywords - Nursing Scheduling Issues, Integer Linear Programming, LINGO.

\section{INTRODUCTION}

The problem of nurse scheduling is an important issue that must be considered in every hospital, good nurse scheduling must be applied in every hospital so that ongoing activities are not interrupted and more optimal. Errors in arranging the scheduling of nurses at the hospital can make them work less optimally so they are prone to making mistakes and will endanger every patient in the hospital. Nurse scheduling problem or known as Nurse Scheduling Problem (NSP) (Hakim, Bakhtiar, \& Jaharuddin, 2017) (Jafari \& Salmasi, 2015), NSP is a nurse scheduling problem at the hospital in arranging the shift scheduling for each nurse. Nursing scheduling problems at hospitals often occur because many hospitals do manual scheduling. Scheduling nurses manually is ineffective and inefficient wherein arranging the scheduling must pay attention to the limited number of nurses that exist and must pay attention to the uniformity of the schedule given to each nurse.
In this study, the authors tried to solve the problem of scheduling nurses applying the Integer Linear Programming model and the branch and bound method, then processed using the LINGO application. Branch and bound algorithm is one method that can be used to solve Integer Programming cases. This method divides the problem into sub-problems that lead to solutions by forming a search tree structure and limiting it to achieve an optimal solution (Sumathi, 2016) (Bakhtiar \& Jaharuddin, 2017). Branch and Bound algorithm procedures are carried out repeatedly to form a search tree and bounding process by determining the upper bound and lower bound in finding the optimal solution (Suryawan, Tastrawati, \& Sari, 2016)

\section{Literature Review}

(Angeline, Iryanto, \& Tarigan, 2014) apply the branch and bound method in determining the optimum amount of production at $\mathrm{Cv}$. $\mathrm{Xyz}$, in his 
research, reviewed based on the amount of raw material inventory, market demand, profits, and time of manufacture of each pant. The results showed that the optimal amount of production of each type of pants (men's trousers, women's trousers, men's shorts, women's shorts). (Nur \& Abdal, 2016) Using the branch and bound and memory cut methods in determining integer linear programming solutions, the results of the Branch and Bound and Gomory Cut methods can be used to solve linear integer programming problems. Based on the case examples given, the same results were obtained between the Branch and Bound and Gomory Cut methods, where the company had to produce 47 A flashlights, $62 \mathrm{~B}$ flashlights, and $172 \mathrm{C}$ flashlights in order to produce an optimum profit of 2,233,000. In the process of completion, the branch and bound method require a large number of simplex iterations and a log time but more convergence is guaranteed. (Suryawan, Tastrawati, \& Sari, 2016) Applying the branch and bound algorithm method in optimizing bread production results in a $25.2 \%$ increase in profits through calculations by applying the branch and bound algorithm. (Rafeek \& Siswanto, 2015) Make an ITS course schedule and then develop an integer programming (ILP) method to solve NP-Complete problems using LINGO software. (Hasan \& Arefin, 2017)

\section{Proposed Method}

\section{Datasheet}

The data used in this study were taken from Cut Nyak Dien Tapak Tuan Aceh Selatan Hospital, taking into account the rules set at the hospital, each nurse would be scheduled with a fair amount of work and shift where all nurses who worked no more than 22 days work, nurses work no more than one shift a day, each nurse works no more than 6 days a week, each nurse works no more than 48 hours a week, if every nurse on duty at the night shift should not be followed by a morning shift the next day, the nurse's schedule must meet the minimum number of nurses needed in each shift every day, nurses who work on the night shift for 2 consecutive days in one week then the next day is given a day off, and each nurse works no more than 2-night shift in one week.

\section{Modeling}

After the stage of formulating the problem, the next step is to represent the problem in the mathematical model. Through this model, the problem is described as a system of equations or other inequalities and mathematical expressions. Nurse work scheduling problems can be modeled as Integer Linear Programming (ILP) (KOÇ \& AKTAN, 2019).

\section{Model solution}

A mathematical model for solving real problems requires computer performance. To get the scheduling model solution, LINGO software is used with the branch and bound method. Then the solution obtained is the solution that most accommodates all restrictions and minimizes the objective function.

The definition of notation that will be used in this model is

Index:

$$
\begin{aligned}
& i=\operatorname{Nurse}(i=1,2, \ldots, I) . \\
& j=\operatorname{Shift}(j=1, \ldots, J) . \\
& 1=\text { Morning Shift (pukul 07.00-14.00). } \\
& 2=\text { Afternoon Shift (pukul 14.00-21.00). } \\
& \quad 3=\text { Night Shift }(\text { pukul 21.00-07.00). } \\
& k=\text { Day }(k=1,2, \ldots, K) . \\
& T \quad=\text { Total working days in the one month }
\end{aligned}
$$
assignment period.

$a=$ The time constant in the day for one-week assignment.

$b=$ The time constant in hours for one week of assignment.

$c$ = Constant length of work time for each shift.

$d_{j k}=$ The number of nurses working for each shift $\mathrm{j}$ on day $\mathrm{k}$.

Variabel keputusan:

$$
x_{i j k}= \begin{cases}1, & \text { jika perawat } i \text { bekerja di shift } j \text { pada } \\ 0, & \text { hari } k \text {. selainnya }\end{cases}
$$

$y 1_{i}=$ Deviation of the shortage of workdays for each nurse $i$ (slack variable)

$y 2_{i}=$ Deviation of excess workdays for each nurse $\mathrm{i}$ (variable surplus).

Fungsi tujuan adalah meminimumkan total deviasi dari kendala penyimpangan hari kerja perawat.

$$
\operatorname{Min} z=\sum_{i=1}^{l} y 1_{i}+y 2_{i}
$$

Constraints:

1. Total of the number of workdays per nurse and deviation of workdays in one month $\mathrm{T}$ days, 


$$
\left(\sum_{j=1}^{J} \sum_{k=1}^{K} x_{i j k}\right)+y 1_{i}-y 2_{i}=T \quad \forall i=1, \ldots, I
$$

2. Each nurse works no more than one shift every day,

$\sum_{j=1}^{J} x_{i j k} \leq 1 \quad \forall i=1, \ldots, I, \quad \forall k=1, \ldots, 24$

3. Each nurse works no more than a day a week,

$$
\begin{aligned}
\sum_{j=1}^{J} \sum_{t=1}^{7} x_{i j(k-t+7)} & \leq a \quad \forall i=1, \ldots, I, \quad \forall k \\
& =1, \ldots, 24
\end{aligned}
$$

4. Each nurse works no more than b hours a week with long hours of work $\mathrm{c}$ hours per shift $t$,

$$
\begin{gathered}
\sum_{j=1}^{J} \sum_{t=1}^{7} c \cdot x_{i j(k-t+7)} \leq b \quad \forall i=1, \ldots, I, \quad \forall k \\
=1, \ldots, 24
\end{gathered}
$$

5. Every nurse on duty at the night shift may not be followed by the morning shift the next day.

$$
\begin{gathered}
x_{i 3 k}+x_{l 1(k+1)} \leq 1 \quad \forall i=1, \ldots, I, \quad \forall k \\
=1, \ldots, K
\end{gathered}
$$

6. The nurse schedules must meet the need for a minimum number of nurses in each shift each day,

$$
\begin{gathered}
\sum_{i=1}^{I} x_{i j k} \geq d_{j k} \quad \forall j=1, \ldots, J, \quad \forall k \\
=1, \ldots, K
\end{gathered}
$$

7. If each nurse is on night shifts for two consecutive days, then the next day off,

$$
\begin{array}{r}
x_{i 3 k}+x_{i 3(k+l)}+\sum_{j=1}^{3} x_{i j(k+2)} \leq 2 \quad \forall i \\
=1, \ldots, I, \quad \forall k=1, \ldots, K
\end{array}
$$

8. Each nurse works no more than 2-night shifts in one week,

$$
\begin{gathered}
\sum_{t=1}^{7} x_{i 3(k-l+7)} \leq 2 \quad \forall i=1, \ldots, I, \quad \forall k \\
=1, \ldots, 24
\end{gathered}
$$

9. The head nurse gets a vacation every Sunday,

$$
\begin{aligned}
& x_{1 j(7 k-d+1)}=0 \quad \forall j=1, \ldots, J, \quad \forall k \\
& =1, \ldots, 4, \quad d=1, \ldots, 7
\end{aligned}
$$

10. Limitation of negative and integer.

$$
\begin{aligned}
x_{i j k} \in\{0,1\} \quad \forall i=1, \ldots, I, \quad \forall k \\
=1, \ldots, J, \quad \forall k=1, \ldots, K
\end{aligned}
$$

\section{RESULT AND DISCUSSION}

1. Nurse Scheduling Results in several Rooms.

After the mathematical model is formulated with the form of Integer Linear Programming, then processed using LINGO with the branch and bound method the nurses work schedule is generated for the emergency room nursing room, class, and ward at the General Hospital in one month with a minimum deviation of working days. Nurses' work schedules in each part of the room from the modeling results provide information on comparing working day deviations between manual scheduling and the new scheduling in September, as well as the total workdays of each nurse on morning, evening and night shifts. The need for a minimum number of nurses in each part of the room in the General Hospital from the modeling results is in accordance with the number of nurses needed. Working days and holidays for each nurse has fulfilled the hospital management's requirements.

Implementation of the model that has been obtained is done by means of model simulation. The simulation uses data on the number of nurses and the need for the number of nurses every day in each section of the room at the General Hospital.

The schedule arranged meets the rules set, namely:

- All nurses who work do not deviate from 22 working days.

- Nurses work no more than one shift in one day.

- Each nurse works no more than 6 days a week.

- Each nurse works no more than 48 hours a week.

- If every nurse on duty at night shift then it should not be followed by the morning shift the next day.

- The nurse schedules must meet the need for a minimum number of nurses in each shift each day 
- Nurses who work on the night shift for 2 consecutive days in one week then the next day is given a day off.

- Each nurse works no more than 2-night shifts in one week.

- There are nurses who cannot be scheduled on certain days. The head nurse is given a day off on Sundays.

The results of mathematical modeling formulated in the form of Integer Linear Programming and processed using LINGO software using the branch and bound method can be seen in the table below:

Table 1. Comparison of Deviations from Emergency Room Nurse Workdays

\begin{tabular}{|c|c|c|c|c|c|c|}
\hline \multicolumn{7}{|c|}{ Manual Schedule Emergency Room } \\
\hline Nurse & $\begin{array}{c}\text { Mor } \\
\text { ning }\end{array}$ & $\begin{array}{c}\text { After } \\
\text { noon }\end{array}$ & $\begin{array}{c}\text { Nig } \\
\text { ht }\end{array}$ & Total & KB & KK \\
\hline 1 & 11 & 11 & 1 & 22 & 1 & 0 \\
\hline 2 & 8 & 8 & 7 & 23 & 1 & 0 \\
\hline 3 & 7 & 8 & 7 & 22 & 0 & 0 \\
\hline 4 & 6 & 9 & 7 & 22 & 0 & 0 \\
\hline 5 & 6 & 9 & 6 & 21 & 0 & 1 \\
\hline 6 & 7 & 7 & 9 & 23 & 1 & 0 \\
\hline 7 & 6 & 8 & 8 & 22 & 0 & 0 \\
\hline 8 & 10 & 6 & 7 & 23 & 1 & 0 \\
\hline 9 & 10 & 4 & 8 & 22 & 0 & 0 \\
\hline 10 & 6 & 10 & 7 & 23 & 1 & 0 \\
\hline 11 & 5 & 10 & 7 & 22 & 0 & 0 \\
\hline 12 & 8 & 7 & 7 & 22 & 0 & 0 \\
\hline 13 & 7 & 6 & 9 & 22 & 0 & 0 \\
\hline 14 & 9 & 7 & 6 & 22 & 0 & 0 \\
\hline & \multicolumn{7}{|c|}{ Amount } & & 5 & 1 \\
\hline & & & & 6 \\
\hline
\end{tabular}

\begin{tabular}{|c|c|c|c|c|c|c|}
\hline \multicolumn{7}{|c|}{ New Model Emergency Room } \\
\hline Nurse & $\begin{array}{c}\text { Mor } \\
\text { ning }\end{array}$ & $\begin{array}{c}\text { Aftern } \\
\text { oon }\end{array}$ & $\begin{array}{c}\text { Nig } \\
\text { ht }\end{array}$ & Total & KB & KK \\
\hline 1 & 8 & 9 & 5 & 22 & 0 & 0 \\
\hline 2 & 11 & 4 & 7 & 22 & 0 & 0 \\
\hline 3 & 7 & 8 & 7 & 22 & 0 & 0 \\
\hline 4 & 9 & 6 & 7 & 22 & 0 & 0 \\
\hline 5 & 10 & 7 & 5 & 22 & 0 & 0 \\
\hline 6 & 8 & 7 & 7 & 22 & 0 & 0 \\
\hline 7 & 10 & 7 & 5 & 22 & 0 & 0 \\
\hline 8 & 14 & 2 & 6 & 22 & 0 & 0 \\
\hline 9 & 10 & 6 & 6 & 22 & 0 & 0 \\
\hline 10 & 8 & 7 & 7 & 22 & 0 & 0 \\
\hline 11 & 9 & 5 & 8 & 22 & 0 & 0 \\
\hline 12 & 7 & 8 & 7 & 22 & 0 & 0 \\
\hline 13 & 8 & 7 & 7 & 22 & 0 & 0 \\
\hline 14 & 4 & 12 & 7 & 22 & 0 & 0 \\
\hline & & Amount & & 0 & 0 \\
\hline & \multicolumn{2}{|c|}{ Total Deviations } & & 0 \\
\hline
\end{tabular}

In table 1. it can be seen that a comparison of the scheduling model between the manual model and the new scheduling model in September shows that the new scheduling model gives all nurses a more equitable number of working days. In the new scheduling model, there are no deviations from workdays compared to manual scheduling which there are deviations of 6 workdays with excess 5 days and a deficiency of 1 workday can be seen in Table 1 , The new schedule considers holidays, night shifts and workday needs of each nurse, so that the new schedule has paid attention to the nurses fatigue factor.

Table 2. Comparison of Classroom Nurse Workday Deviations. 


\begin{tabular}{|c|c|c|c|c|c|c|}
\hline \multicolumn{7}{|c|}{ Manual Schedule Class Nursing Room } \\
\hline Nurse & $\begin{array}{c}\text { Mor } \\
\text { ning }\end{array}$ & $\begin{array}{c}\text { Aftern } \\
\text { oon }\end{array}$ & $\begin{array}{c}\text { Nig } \\
\text { ht }\end{array}$ & Total & KB & KK \\
\hline 1 & 15 & 8 & 0 & 22 & 1 & 0 \\
\hline 2 & 11 & 6 & 6 & 23 & 1 & 0 \\
\hline 3 & 9 & 6 & 7 & 22 & 0 & 0 \\
\hline 4 & 6 & 7 & 9 & 22 & 0 & 0 \\
\hline 5 & 8 & 7 & 7 & 22 & 0 & 0 \\
\hline 6 & 7 & 7 & 8 & 22 & 0 & 0 \\
\hline 7 & 8 & 5 & 9 & 22 & 0 & 0 \\
\hline 8 & 9 & 6 & 7 & 22 & 0 & 0 \\
\hline 9 & 9 & 8 & 6 & 22 & 0 & 0 \\
\hline 10 & 8 & 9 & 5 & 22 & 0 & 0 \\
\hline 11 & 11 & 4 & 7 & 22 & 0 & 0 \\
\hline 12 & 7 & 6 & 8 & 21 & 0 & 1 \\
\hline 13 & 4 & 11 & 6 & 21 & 0 & 1 \\
\hline 14 & 6 & 9 & 7 & 22 & 0 & 0 \\
\hline & & & & 6 & 2 \\
\hline & \multicolumn{2}{|c|}{ Total Deviations } & & 8 \\
\hline
\end{tabular}

In table 2. it can be seen that a comparison of scheduling models between manual models and the new scheduling model in September shows that the new scheduling model provides a more equal number of working days to all nurses. In the new scheduling model there are no deviations from workdays compared to manual scheduling there are deviations of 8 working days with excess 6 days and lack of 2 working days can be seen in Table 2. The new schedule considers the holidays, night shifts and workday needs of each nurse, so the new schedule has paid attention to the nurses' fatigue factor.

Table 3. Comparison of Ward Room Worker Day Deviations.

\begin{tabular}{|c|c|c|c|c|c|c|}
\hline \multicolumn{7}{|c|}{ Manual Schedule Ward Room } \\
\hline Nurse & $\begin{array}{c}\text { Mor } \\
\text { ning }\end{array}$ & $\begin{array}{c}\text { Aftern } \\
\text { oon }\end{array}$ & $\begin{array}{c}\text { Nig } \\
\text { ht }\end{array}$ & Total & KB & KK \\
\hline 1 & 20 & 3 & 0 & 23 & 1 & 0 \\
\hline 2 & 10 & 6 & 7 & 23 & 1 & 0 \\
\hline 3 & 7 & 6 & 8 & 21 & 0 & 1 \\
\hline 4 & 5 & 9 & 8 & 22 & 0 & 0 \\
\hline 5 & 6 & 8 & 9 & 23 & 1 & 0 \\
\hline 6 & 8 & 7 & 9 & 24 & 2 & 0 \\
\hline 7 & 5 & 7 & 9 & 21 & 0 & 1 \\
\hline 8 & 9 & 5 & 8 & 22 & 0 & 0 \\
\hline 9 & 5 & 7 & 10 & 22 & 0 & 0 \\
\hline 10 & 5 & 7 & 9 & 21 & 0 & 1 \\
\hline 11 & 7 & 6 & 8 & 21 & 0 & 1 \\
\hline 12 & 8 & 5 & 9 & 22 & 1 & 0 \\
\hline 13 & 5 & 8 & 8 & 21 & 0 & 1 \\
\hline 14 & 6 & 7 & 9 & 22 & 0 & 0 \\
\hline & & Amount & & 9 & 5 \\
\hline & \multicolumn{2}{|c|}{ Total Deviations } & & 14 \\
\hline
\end{tabular}

\begin{tabular}{|c|c|c|c|c|c|c|}
\hline \multicolumn{7}{|c|}{ New Model Class Nursing Room } \\
\hline Nurse & $\begin{array}{c}\text { Mor } \\
\text { ning }\end{array}$ & $\begin{array}{c}\text { Aftern } \\
\text { oon }\end{array}$ & $\begin{array}{c}\text { Nig } \\
\text { ht }\end{array}$ & Total & KB & KK \\
\hline 1 & 8 & 9 & 5 & 22 & 0 & 0 \\
\hline 2 & 8 & 7 & 7 & 22 & 0 & 0 \\
\hline 3 & 8 & 7 & 7 & 22 & 0 & 0 \\
\hline 4 & 10 & 7 & 5 & 22 & 0 & 0 \\
\hline 5 & 15 & 2 & 5 & 22 & 0 & 0 \\
\hline 6 & 8 & 7 & 7 & 22 & 0 & 0 \\
\hline 7 & 8 & 7 & 7 & 22 & 0 & 0 \\
\hline 8 & 9 & 6 & 7 & 22 & 0 & 0 \\
\hline 9 & 4 & 10 & 8 & 22 & 0 & 0 \\
\hline 10 & 7 & 11 & 4 & 22 & 0 & 0 \\
\hline 11 & 9 & 6 & 7 & 22 & 0 & 0 \\
\hline 12 & 12 & 4 & 6 & 22 & 0 & 0 \\
\hline 13 & 9 & 6 & 7 & 22 & 0 & 0 \\
\hline 14 & 6 & 7 & 9 & 22 & 0 & 0 \\
\hline & \multicolumn{7}{|c|}{ Amount } & & 0 & 0 \\
\hline & \multicolumn{2}{|c|}{ Total Deviations } & & 0 \\
\hline
\end{tabular}




\begin{tabular}{|c|c|c|c|c|c|c|}
\hline \multicolumn{7}{|c|}{ New Model Ward Room } \\
\hline Nurse & $\begin{array}{c}\text { Mor } \\
\text { ning }\end{array}$ & $\begin{array}{c}\text { Aftern } \\
\text { oon }\end{array}$ & $\begin{array}{c}\text { Nig } \\
\text { ht }\end{array}$ & Total & KB & KK \\
\hline 1 & 10 & 7 & 5 & 22 & 0 & 0 \\
\hline 2 & 13 & 4 & 5 & 22 & 0 & 0 \\
\hline 3 & 14 & 2 & 6 & 22 & 0 & 0 \\
\hline 4 & 10 & 6 & 6 & 22 & 0 & 0 \\
\hline 5 & 12 & 3 & 7 & 22 & 0 & 0 \\
\hline 6 & 9 & 5 & 8 & 22 & 0 & 0 \\
\hline 7 & 8 & 7 & 7 & 22 & 0 & 0 \\
\hline 8 & 11 & 5 & 6 & 22 & 0 & 0 \\
\hline 9 & 13 & 3 & 6 & 22 & 0 & 0 \\
\hline 10 & 11 & 5 & 6 & 22 & 0 & 0 \\
\hline 11 & 8 & 6 & 8 & 22 & 0 & 0 \\
\hline 12 & 9 & 5 & 8 & 22 & 0 & 0 \\
\hline 13 & 11 & 4 & 7 & 22 & 0 & 0 \\
\hline 14 & 10 & 5 & 7 & 22 & 0 & 0 \\
\hline & & Amount & & 0 & 0 \\
\hline & \multicolumn{2}{|c|}{ Total Deviations } & & 0 \\
\hline
\end{tabular}

In table 3. it can be seen that a comparison of scheduling models between manual models and the new scheduling model in September shows that the new scheduling model provides a more equal number of workdays to all nurses. In the new scheduling model there are no deviations from workdays compared to manual scheduling there are deviations of 13 workdays with excess 9 days and a deficiency of 5 workdays can be seen in Table 3 . The new schedule considers the holidays, night shifts and workday needs of each nurse so that the new schedule has paid attention to the fatigue factor of nurses.

\section{CONCluSion AND SUgGeStion}

\section{Conclusion}

Based on the results, the conclusions that can be drawn are:

- Nurse scheduling modeling can solve nurses scheduling problems that minimize the deviation (deviation) of each nurse's workday.

- Development of the scheduling model with the rules recommended by the General Hospital in modeling nurses scheduling more effectively. This can be seen in the new schedule for the number of nurses fulfilled, setting the number of night shifts and the need for days off accordingly.

- The scheduling model that produces a new schedule already regulates the need for days off and night shifts so that attention is paid to the nurse's fatigue.

\section{Suggestion}

- This research can be developed to solve scheduling problems with a greater number of nurses.

- Research can also be developed by completing various cases of nurse scheduling by considering nurse requests on night shifts and days off so that the level of nurse satisfaction is met.

\section{REFERENCES}

Angeline, A., Iryanto, I., \& Tarigan, G. (2014). Penerapan metode branch and bound dalam menentukan jumlah produksi optimum pada cv. Xyz. Saintia Matematika , 2 (2), 137145.

Bakhtiar, H. T., \& Jaharuddin, J. (2017). The nurse scheduling problem: a goal programming and nonlinear optimization approaches. IOP Conference Series: Materials Science and Engineering .

Hakim, L., Bakhtiar, T., \& Jaharuddin, J. (2017). The nurse scheduling problem: a goal programming and nonlinear optimization approaches. Materials Science and Engineering , 1-7.

Hasan, M. M., \& Arefin, M. R. (2017). Aplication Of Linear in Scheduling Problem. Dhaka Univ. J. Sci, 145-150.

Jafari, H., \& Salmasi, N. (2015). Maximizing the nurses' preferences in nurse scheduling problem: mathematical modeling and a meta-heuristic algorithm. J Ind Eng Int .

KOÇ, B. A., \& AKTAN, M. (2019). The Solution of Nurse Scheduling Problem with Simulated Annealing Algorithm. Journal of Scientific and Engineering Research , 6 (4), 153-160.

Nur, W., \& Abdal, N. M. (2016). Penggunaan Metode Branch and Bound dan Gomory Cut. JURNAL SAINTIFIK , 2 (1), 9-15.

Rafeek, F. S., \& Siswanto, N. (2015). Solving Course Timetable Problem by using Integer Linear Programming (Case Study IE Department of 
ITS). International Seminar on Science and Technology.

Sumathi, P. (2016). A new approach to solve linear programming problem with intercept values. Journal of Information \& Optimization Sciences.
Suryawan, G., Tastrawati, N. K., \& Sari, K. (2016). Penerapan branch and bound algorithm dalam optimalisasi produksi roti. E-Jurnal Matematika , 5 (4), 148-155. 